\title{
Teaching Model Application of Three Explorations with Three Problems in Universities
}

\author{
Hongtao Xue* \\ School of Automobile and Traffic Engineering \\ Jiangsu University \\ Zhenjiang, China \\ xueht@ujs.edu.cn \\ Haobin Jiang \\ School of Automobile and Traffic Engineering \\ Jiangsu University \\ Zhenjiang, China \\ jianghb@ujs.edu.cn
}

\author{
Guoqing Geng \\ School of Automobile and Traffic Engineering \\ Jiangsu University \\ Zhenjiang, China \\ 1074500565@qq.com \\ Maotao Zhu \\ School of Automobile and Traffic Engineering \\ Jiangsu University \\ Zhenjiang, China \\ zhumt@ujs.edu.cn
}

\begin{abstract}
This paper presents a novel teaching model called three explorations with three problems (TETP) during the reform process of higher education. The essence of TETP is to divide classroom teaching process into three stages, different levels of problems are solved sequentially by self-exploration, group-cooperation exploration and class-cooperation exploration. TETP fully takes the student as the main character, puts more emphasis on the cultivation of different thinking, and guides the students to find forwardly a problem, ponder independently the one, explore cooperatively the issues, and be good at expanding a new problem from multiple perspectives. Moreover, TETP not only emphasizes the process of repeated explorations which can encourage each student to master knowledge and improve the problem-solving abilities, but also focus on each student's learning situation in each step which is used to evaluate the achievement of learning objectives. It conforms to the idea of outcome-based education (OBE) which is advocated by international engineering alliance. Therefore, TETP is the development direction of class te aching reform.
\end{abstract}

Keywords-three explorations with three problems; outcomebased education; teaching reform; engineering education

\section{INTRODUCTION}

Teaching is the center of the universities, the scientific and effective teaching method is selected to realize the teaching goal and ensure the quality of teaching. Thus, many teaching methods have been proposed [1-6]. The simple method of teaching reading was studied on the psycholinguistics [1]. Inquiry-based model was offered to encourage students to become self-directed and engaged learners. Inquiry-based model is widely applicable and will help faculty members from a variety of disciplines develop an innovative way of engaging and teaching students [2]. Group-discussion based model was proposed to enlarge more participation of students, and improve the effectiveness of classroom learning [3]. The teaching method not only arouses the enthusiasm of students'

Supported by Top-notch Academic Programs Project of Jiangsu Higher Education Institutions (PPZY2015A 023), Research Project on Higher Education Reform of Jiangsu Province (2017JSJG033) and Research Project on Higher Education Reform of Jiangsu University (2015JGYB020) leaning, but also develops creativity among students. It has been proved that group-discussion method especially students' perception and ratings is an effective way. Certainly, other traditional teaching methods such as lecture method, practice teaching, objects teaching, etc. are often used in the college teaching class [4-6].

In the wake of developments in science and technology, new teaching models were presented to explore and research. For example, electronic classroom such as World Wide Web was presented to broaden students' perceptions [7]. Massive Open Online Course (MOOC) was recommended during the reform process of higher education. It is obvious that MOOC is offered good learning platforms which can autonomy, diversity, openness and connectedness/interactivity [8]. Case method of teaching was applied to solve the features and problems of computer foundation [9]. Micro-Lesson was introduced into the instructional technology course of the teacher education program to provide pre-service teachers with opportunities to adopt constructivist instructional approaches towards the design of multimedia learning packages [10]. Certainly, there are many teaching methods in the teaching or learning process. These methods enrich teaching activities. However, modern teaching methods usually rely on the internet or new media. Therefore, many methods of modern teaching are only regarded as a useful complement of classroom teaching.

For elementary and higher education, classroom teaching is still the main position. Then how to raise classroom teaching efficiency and teaching quality, and cultivate student's learning interest and problems-solving ability is the eternal theme that numerous teaching and researching staff have been discussing. In recent years, the steps of the university reform in education especially engineering education were accelerated; the evaluation of university student's quality such as the practical abilities of problems-discovering and problems-solving was incessant brought into focus. For expanding the exchanges and cooperation of international engineering education, the idea of outcome-based education (OBE) was advocated by 
international engineering alliance, and regarded as part of Washington Accord [11-13]. In 2016, China formally became a member of the Washington Accord. It further promotes the reform of Chinese higher education, especially the engineering education. At the same time, how to select a suitable classroom teaching method which can implement the OBE's idea has also become an important subject currently.

The teaching model of three explorations with three questions (TETP) is a new teaching idea which was summarized from teaching practice. TETP not only fuses the ideas of problem, heuristic, inquiry, discussion educations, but also emphasizes the process of repeated explorations and student's learning situation such as knowledge acquisition and applied abilities. Therefore, TETP completely conforms to the OBE's idea. Moreover, the teaching classroom of TETP is refined into three stages; the task of each stage is to solve different levels of problems by self-exploration, groupcooperation exploration and class-cooperation exploration. The teaching model is very maneuverable.

\section{TEACHING IDEA OF TETP}

The nature of three explorations with three problems (TETP) is three major stages of teaching classroom which is used to solve the different levels of problems. In the first stage, each teacher needs to create problem situation and put some problems around learning target, each student learns by himself and masters related knowledge under the guidance of some problems and learning target. When some problems are met, each student self-explores and self-discovers to search the methods of problems-solving by textbook, assistant book or network. So the first stage is call as "self-exploration with putting problems". Certainly, most of putting problems by teacher can be solved after student self-exploration, and some problems cannot be solved. Moreover, the problems solved from different students are different. Then each student with problems is guided to enter the second stage by teacher. Through group-cooperation exploration, self-exploration condition is commutatively detected. One of some students who already have mastered knowledge or found the method of solving problem can teach other, other students learn or selfdetect. Certainly, when different suggestions are met, the whole group can discuss or explore together until equivocal problems are solving. So the second stage is call as "group-cooperation exploration with equivocal problems". Similarly, there are some problems cannot be solving or solving suggestions cannot be unitive in a group. Then the third stage of class-cooperation exploration is propelled. In general, the problems in third stage are more difficult, and correspond to teaching difficult points. However, each group has its own opinion on the basis of group-cooperation exploration, and the emphasis and analysis directions of these opinions are different. Through classcooperation exploration, the problems are analyzed deeply and extensive views are exchanged, each student can find the method of solving problems. So the third stage is called as "class-cooperation exploration with questioning problems" [14$16]$.

Each lesson is studied through reiterative explorations, primary knowledge must be mastered and the problems-solving methods can be practiced and understood. More importantly, students are trained through the teaching model of TETP, the abilities of self-discovering problem, self-exploring problem and problem-expression can be improved. Different thinking and creative spirit are also cultivated. This is the teaching idea of TETP.

\section{FEATURES OF TETP TEACHING}

The teaching idea of TETP advocate students to selfdiscover and self-solve problems, all activities that can be completed by students must be handed to students, even then for some problems that cannot be completed by students, the teacher must have the courage and wisdom to hand these problems to students and give them more opportunity of selfexploration. In class, the teacher is one of the audience who must watch each student's exploration feedback and share the joy of each student after each question is solved. Only when student's exploration was in trouble or exploring direction diverged from the learning goals, the teacher will inspire or guide appropriately the students to rethink and explore until the problem is solved $[14,16]$. Therefore, there must be two elements if TETP is implemented smoothly. Firstly, the teacher has a comprehensive professional knowledge and inductive ability which multiple problems are set around the learning target, key points and difficult points. Secondly, most of students have certain abilities of autonomous learning. It is obvious that students and teachers have the corresponding condition in university; especially the college students have a wider range of knowledge, stronger ability of autonomous learning, and more methods using modern tools.

Moreover, when TETP is implemented, the teacher cannot involve heavily in students' exploration progress. So the initiative of teaching progress is entirely in the hands of students. Then it is difficult to predict students' difficult points in the process of exploration. The phenomenon is likely to occur that learning target cannot be completed according to original plan in class. However, two hours are adopted for each teaching arrangement in university. It is useful to adjust neatly some teaching tasks on the local scale. Therefore, TETP teaching adapted to university classroom.

\section{TETP'S TEACHING IDEA CONFORMS TO THE REQUIREMENTS OF HIGHER EDUCATION}

The state and party especially university often propose to improve teaching level and innovation ability. College students are significant players in the coming society, and then their abilities of discovering, parsing and solving problems, innovation spirit, cooperative consciousness, and expression abilities are always the focuses concerned by the government and society, especially in recent years. With the rapid development of various countries' economies in the world, many emerging industries develop quickly, and many new techniques suck as artificial intelligence (AI), cloud computing, big data mining, biological science, etc. become the focus of study and research. As the bases for talent cultivation in the new era, universities must conform to the development of The Times, and produce a large number of qualified personnel. Therefore, there must be further reform in higher education, 
and the revolution of higher education must base on the revolution of teaching method.

The teaching method of TETP always clasp "problem” and "exploration", teaching activities start from the doubt until the doubt is clarified. William Heard Kilpatrick who was an educator in American put forward the design method of teaching. The method has advocated teaching activities on students' independent activities, learning style is to solve some problems, and the intrinsic interest and initiative of students can be stimulated [17]. In this way, knowledge connotation is grasped in repeated explorations, and the methods of problemdiscovering and problem-solving are applied slickly. In the long run, innovation thinking and practice ability of each student can be improved greatly, cooperative consciousness and expression ability are also trained. This conforms to the requirements of the teaching method reform in university.

\section{A. Enhancing the ability of active learning}

In today's society with rapid development of science and technology, new knowledge and new technologies are on the increase, and the update cycles are shorter [18]. Universities should not only emphasize the bookish knowledge, but cultivate the ability of active learning through the limited classroom teaching. Moreover, each student is guided sequentially to set up the consciousness of lifelong learning. Only in the way can universities conform to the needs of talent cultivation, and then each student can meet the requirement of social development.

The teaching method of TETP advocates that each student is trained to cultivate the ability of active learning from the bookish knowledge to some extra-curricular knowledge in each classroom teaching. Through problem situation and putting some problems, the learning interest of each student is aroused, and student's knowledge is enriched, then the ability of active learning is enhanced and the habit of active learning is formed. In future, when new knowledge and new technologies are meet, each student has the ability of problem-solving, also has confidence in new problem-solving. At time passes, learning motivation is redeployed in practice and innovation, and then the consciousness of lifelong learning is also established.

\section{B. Strengthening the awareness of teamwork}

Under the background of international engineering education accreditation and new engineering construction, many industries and production systems have involved the integration of much knowledge and the cross of multidisciplinary [19, 20]. Therefore, the awareness of teamwork have attracted much attention. How to develop teamwork spirit and strengthen teamwork awareness is one of the course contents that universities need to intensify.

The teaching model of TETP sets specially two teaching links of group-cooperation exploration and class-cooperation exploration. Through group discussion and class interaction, each student can find own skilled contents and lead other students to master the relevant contents, and then may draw forth one's latent abilities. Above all, these teaching links are insisted for a long time to develop teamwork spirit and strengthen teamwork awareness.

\section{Emphasis on the cultivation of divergent thinking}

J.P. Guilford who was a psychologist in American believed that a person's divergent thinking could expand his approaches to creativity, and the more a person's thinking was divergent, the more his creativity was outstanding. The best way that the ability of a person's thinking is exercised and improved people's thinking ability is to participate the thinking practice [21]. The teaching links of TETP set three stages. In the first stage, different levels of problems are introduced by teachers to set the range of thinking practice. Round these problems, different students have different thinking; textbook, assistant book and network can be used to find proper answers or suitable methods. In the second and third links, different answers and methods are introduced and discussed. In fact, this is not only the learning process, but also the judgment process of thinking correctly or not. If each course uses the teaching method of TETP to carry out teaching activities, each student not only participate the thinking practice, but also learn the thinking modes of other students. For a long time, the divergent thinking of each student can be cultivated.

Moreover, the teaching idea of TETP proposes that students would explore to complete learning tasks as soon as possible, and textbook, assistant book and network can be used. Then new knowledge, technology and method that beyond textbooks can be learned and mastered. In the process, divergent thinking of each student is also practiced. Therefore, the teaching idea of TETP is useful to the cultivation of divergent thinking for each student.

\section{Emphasis on the training of communication ability}

The communication ability is explicitly prescribed in the standards of China engineering education accreditation. When each student graduates from college, he can communicate effectively with the industry peers and the social public communication for complex engineering problems, and exchange under the background of cross-cultural communication [22]. Therefore, universities must attach importance to train the communication ability of each student.

Two teaching links of TETP are group discussion and class interaction. In the process, all problem-solving methods need to express in language, and each student has a chance to speak. If expression is inaccurate, it is difficult that the right approach is understood for other students, and then the inaccurate language must be pointed out. Gradually, everyone's communication ability is trained and improved.

\section{E. Emphasis on the attainment of learning goal}

The idea of outcome-based education (OBE) has be recognized by many countries include China. In recent years, China Engineering Education Accreditation Association (CEEAA) has made specially the standards of China engineering education accreditation with Washington Agreement. In the standards, training objective has three terms and graduation requirements have twelve terms which include knowledge, professional ethics, the use of modern tools, teamwork spirit, the abilities of problem-analyzing, problemsolving, communication, etc. 
TETP teaching not only attaches importance to the cultivation of divergent thinking, but also emphasizes the attainment of learning goal. In each teaching link, the exploration condition of each student is examined and evaluated in the next link. Certainly, the means of examination and evaluation is various. For example, mutual evaluation, teacher comment and results show. Moreover, teachers can put some practical cases to check the expansion and application of knowledge. Teachers should adjust the learning process according to the situation of examination and evaluation. If the feedback situation is unsatisfactory, exploration link can be appropriately extended time. Otherwise, next link can be entered early. Therefore, TETP completely conforms to the OBE's idea, and attaches importance to the attainment of learning goal.

\section{CONCLUSION}

TETP has the advanced concept of teaching idea, conforms to the demands of university teaching reform. Moreover, the features of TETP teaching also adapt to university classroom, the maneuverability of TETP teaching is very stronger, and TETP teaching can be applied slickly. How to apply properly the teaching method of TETP for achieving the desired effect, need to practice constantly and improve continuously.

\section{REFERENCES}

[1] F. Smith, and K.S. Goodman, "On the psycholinguistic method of teaching reading,” Elementary School Journal, vol. 71, issue 4, pp. 177181, 1971.

[2] C. Justice, J. Rice, W. Warry, et al, "Inquiry in higher education: reflections and directions on course design and teaching methods," Innovative Higher Education, vol. 31, issue 4, pp. 201-214, 2007.

[3] M. Ling, "Group discussion-based cooperative learning model with teacher's guidance,” Journal of English Studies, 2013.

[4] A.E. Covill, "College students' perceptions of the traditional lecture method,” College Student Journal, vol. 45, issue 1, pp. 92-101, 2011.

[5] Y. L. Yuan, "The practice and effect of developmental teaching method on nursing students' self-directed learning ability,” Journal of Nursing Administration, 2006.

[6] Y. Lu, and Q. Xu, "Education reform of objects teaching method in the course of men's Wear,” Journal of Zhejiang Sci-Tech University, 2010.
[7] M. Ryan, K.H. Carlton, and N.S. Ali, “Evaluation of traditional classroom teaching methods versus course delivery via the World Wide Web,” Journal of Nursing Education, vol. 38, issue 38, pp. 272-277, 1999.

[8] J. Mackness, F.J.M. Sui, and R. Williams, "The ideals and reality of participating in a MOOC,” Networked Learning Conference, 2010.

[9] J. Qin, "The application of case methods of teaching in teaching of computer foundation,” Journal of Southwest China Normal University, 2010.

[10] Bee Choo Chan, "Micro-lessons in teacher education: Examining preservice teachers' pedagogical beliefs,” Computers \& Education, vol. 48, issue 3, pp. 474-494, 2007.

[11] Spady, G. William, Marshall, and J. Kit, “Beyond traditional outcomebased education,” Educational Leadership, vol. 49, issue 2, pp. 67-72, 1991.

[12] R. M. Harden, "Developments in outcome-based education,” Medical Teacher, vol. 24, issue 2, pp. 117-120, 2002.

[13] R. M. Harden, "Outcome-based education: the future is today," Medical Teacher, vol. 29, issue 7, pp. 625-629, 2007.

[14] W.P. Yang, "How to apply correctly teaching model of three explorations with three problems,” New Education, vol. 1, pp. 11-11, 2009. In Chinese.

[15] X.R. Qiang, “Teaching model application of three explorations with three problems in Chinese teaching of primary school," Development, vol. 7, pp. 143-143, 2010. In Chinese.

[16] H. Xue, Z. Li, and H. Jiang, "Teaching model application of three explorations with three problems in university teaching", New Curriculum Research, vol. 2016, issue 6, pp. 39-40, 2016. In Chinese.

[17] L.M. Yao, "Review on the study of teaching method in higher educational institutions," University Education Science, vol. 119, pp. 2029, 2010. In Chinese.

[18] M. Breuilly, G. Malandain, J. Guglielmi, et al, "A mplitude-based data selection for optimal retrospective reconstruction in micro-SPECT," Physics in Medicine \& Biology, vol. 58, issue 8, pp. 2657, 2013.

[19] J. Yang, "Knowledge integration and innovation: Securing new product advantage in high technology industry,” Journal of High Technology Management Research, vol. 16, issue 1, pp. 121-135, 2005.

[20] Rossi, Dolene, “Learning interactions: a cross-institutional multidisciplinary analysis of learner-learner and learner-teacher and learnercontent interactions in online learning contexts, 2013.

[21] J.B. Stroud, 'Fundamental statistics in psychology and education," McGraw-Hill, 1950.

[22] China Engineering Education Accreditation Association, "The standards of China engineering education accreditation,” http://www.ceeaa.org.cn. 